\title{
Objective assessment of surgeon kinematics during simulated laparoscopic surgery: a preliminary evaluation of the effect of high body mass index models
}

\author{
Ryan Sers ${ }^{1}\left[\right.$. Steph Forrester ${ }^{1} \cdot$ Massimiliano Zecca $^{1} \cdot$ Stephen Ward ${ }^{1} \cdot$ Esther Moss $^{2}$
}

Received: 11 March 2021 / Accepted: 6 July 2021 / Published online: 24 July 2021

(C) The Author(s) 2021

\begin{abstract}
Purpose Laparoscopy is used in many surgical specialties. Subjective reports have suggested that performing laparoscopic surgery in patients with a high body mass index (BMI) is leading to increased prevalence of musculoskeletal symptoms in surgeons. The aim of this study was to objectively quantify the impact on surgeon upper body kinematics and dynamic workload when performing simulated laparoscopy at different BMI levels.

Methods Upper body kinematics and dynamic workload of novice, intermediate and expert surgeons were calculated based on measurements from inertial measurement units positioned on upper body segments. Varying thicknesses of foam were used to simulate patient BMIs of 20,30, 40 and $50 \mathrm{~kg} / \mathrm{m}^{2}$ during laparoscopic training.

Results Significant increases in the jerkiness, angular speed and cumulative displacement of the head, torso and upper arms were found within all experience groups when subject to the 40 and $50 \mathrm{~kg} / \mathrm{m}^{2}$ models. Novice surgeons were found to have less controlled kinematics and larger dynamic workloads compared to the more experienced surgeons.

Conclusions Our findings indicate that performing laparoscopic surgery on a high BMI model worsens upper body motion efficiency and efficacy, and increases dynamic workload, producing conditions that are more physically demanding when compared to operating on a $20 \mathrm{~kg} / \mathrm{m}^{2}$ model. These findings also suggest that the head, torso, and upper arm segments are especially affected by high BMI models and therefore exposure to patients with high BMIs may increase the risk of musculoskeletal injury when performing laparoscopic surgery.
\end{abstract}

Keywords Laparoscopic surgery $\cdot$ Obesity $\cdot$ IMU $\cdot$ Kinematics $\cdot$ Workload

\section{Introduction}

Obesity has become one of the most prominent global health risks, with an incidence at an all-time high [1]. Body mass index (BMI), used as an indicator of body composition throughout healthcare, subdivides obesity into three categories: Class 1, BMI of $30 \mathrm{~kg} / \mathrm{m}^{2}$ to $<35 \mathrm{~kg} / \mathrm{m}^{2}$, Class 2, BMI of $35 \mathrm{~kg} / \mathrm{m}^{2}$ to $<40 \mathrm{~kg} / \mathrm{m}^{2}$ and Class 3 , BMI of $\geq 40 \mathrm{~kg} /$ $\mathrm{m}^{2}$ often termed as 'severe' [1]. Obesity levels in England

Esther Moss

em321@1e.ac.uk

1 Wolfson School of Mechanical, Electrical and Manufacturing Engineering, Loughborough University, Loughborough, UK

2 Leicester Cancer Research Centre, University of Leicester, University Road, Leicester LE1 7RH, UK have increased from 15\% of the adult population in 1993 to $27 \%$ in 2015 [2], with current projections of over 4 million adults with severe obesity by 2035 across England, Scotland and Wales [3].

Obesity is reported to be the second largest preventable cause of cancer and is linked to many malignancies, such as endometrial cancer [4]. Minimally invasive surgery (MIS), and specifically laparoscopic surgery (LS), is a primary method of treatment for many obesity-related cancers as the technique has a significantly better peri-operative morbidity/ mortality rate compared to open surgery [5].

Laparoscopic surgery is associated with a significantly greater risk of work-related musculoskeletal disorders (MSDs) in surgeons, compared to open or robotic-assisted surgery [6]. The neck, back, shoulders, and knees are the most commonly reported symptom areas [7]. MSDs have a complex multifactorial aetiology; however, in surgeons, the incidence of such disorders is most widely attributed to 
the physical demands associated with LS including extreme operating postures leading to high muscular loading around the neck and trunk combined with awkward and repetitive upper arm movements, both experienced over extended periods of time [6, 7]. Additional contributing factors to MSDs include a higher number of surgeries performed in a given time period and patients with obesity [8]. While surgeons have anecdotally associated procedures on patients with high BMIs with increased workload, little objective research exists into understanding whether this statement has validity.

Recent studies have assessed the differences in surgeon muscle activity and kinematics when performing LS at BMIs $<30 \mathrm{~kg} / \mathrm{m}^{2}$ (non-obese) and between 30 and $35 \mathrm{~kg} /$ $\mathrm{m}^{2}$ (Class 1) [9, 10]. Specifically, the first study assessed muscular stress of surgeons performing live LS by measuring muscle activity using electromyography finding no significant differences between BMI levels for all upper body muscles [9]. The second study measured the muscle activity of the back and the motion of the upper body using inertial measurement units (IMUs) fixed on the waist, torso, shoulders and upper arms when completing simulated LS and found significant differences $(p<0.05)$ in torso angular motion between BMI levels [10]. However, given the growing prevalence of severe obesity, studies investigating the effects of BMIs $\geq 40 \mathrm{~kg} / \mathrm{m}^{2}$ on surgeon kinematics are needed.

The purpose of this study was to assess the impact of different levels of simulated patient BMI on surgeon upper body kinematics and the implications on the subsequent dynamic workload when performing LS. In addition, surgeons of varying experience levels were assessed to investigate the severity of BMI on MIS trainees (novices), early career surgeons (intermediates) and consultants (experts). To assess surgeon upper body kinematics and dynamic workload, two groups of metrics were considered. Firstly, the efficiency and efficacy of upper body kinematics were evaluated through mean linear jerk [11], mean angular speed and the cumulative displacement of body segments [12]. Secondly, global indicators of work done by the surgeon included the cumulative displacement of body segments together with the time required to complete the task [13]. The authors hypothesized that increased BMI would degrade surgeon kinematics and increase their dynamic workloads, and that the deterioration in these factors would be greatest for less experienced surgeons.

\section{Materials and methods}

\section{Participants and ethics}

This study was conducted at Loughborough University, UK. Ethical approval was granted by the University Ethics
Approvals Sub-Committee and all participants provided voluntary informed consent prior to testing. The participant cohort consisted of three senior gynecological surgeons $(10+$ years of LS experience, $>100$ procedures per year, referred to as 'expert' participants), three senior gynecological trainees ( $4-6$ years' LS experience, $>50$ procedures per year, referred to as 'intermediate' participants) and four final year medical students (no live LS experience, referred to as 'novices') (6 males and 4 females, with heights: 168-188 cm, and masses: 59-96 kg). All participants had previous exposure to simulated environments, and all were right hand dominant.

\section{Instrumentation and equipment}

To capture participant kinematics, the Perceptron Neuron inertial motion capture (Mo-Cap) system was used configured in the 18-neuron setup (NOITOM Ltd, China). The MoCap system was setup in this mode despite the use of only 11 upper body sensors because the 18-neuron configuration has been previously validated for motion analysis (Fig. 1) [14]. The setup comprised of 11 inertial measurement units (IMUs); each IMU (size: $12.5 \times 13.1 \times 4.3 \mathrm{~mm}$, mass: $1.2 \mathrm{~g})$ consisted of a 3 -axis accelerometer $( \pm 16 \mathrm{~g})$ and 3-axis gyroscope ( $\pm 2000 \mathrm{dps})$. The IMUs were connected in series to a wireless hub, which transferred the data from the suit's sensors to a dedicated PC (at $120 \mathrm{~Hz}$ ). Participant anthropometrics were measured using an Xbox Kinect 2 (Xbox, Microsoft, Redmond, WA, USA) and used to calibrate the system following its recommended calibration procedure [15]. The sensor data were then streamed into MATLAB 2019b (MATLAB, MathWorks, Natick, MA, USA) via TCP/ IP for analysis [16].

Patient BMI was simulated using different thicknesses of foam [10]. The foam $\left(\rho \approx 37 \mathrm{~kg} / \mathrm{m}^{3}\right)$ was securely attached over the ports on the outside of the laparoscopic trainer using Velcro to ensure consistent implementation (Fig. 2). Foam with a thickness of $1.7 \mathrm{~cm}$ was used for the baseline BMI $20 \mathrm{~kg} / \mathrm{m}^{2}, 6.5 \mathrm{~cm}$ for $30 \mathrm{~kg} / \mathrm{m}^{2}, 9.5 \mathrm{~cm}$ for $40 \mathrm{~kg} / \mathrm{m}^{2}$, and $11 \mathrm{~cm}$ for $50 \mathrm{~kg} / \mathrm{m}^{2}$ [17]. The baseline model thickness was based on [18]. The foam thicknesses for all obese models were based on [19]. Moreover, for BMI levels $\geq 40 \mathrm{~kg} / \mathrm{m}^{2}$, a side bar of $7.5 \mathrm{~cm}$ in width was attached to the operating table, creating a wider table as used to accommodate patients with severe obesity in practice [20].

Participant anthropometrics were considered in the setup. An ergonomically optimal surface height has been established as $0.7-0.8$ of a surgeon's elbow height in neutral postures [21]. An acceptable surface height range of $84.6-107.8 \mathrm{~cm}$ was calculated for all surgeons based on their anthropometrics. Therefore, the operating surface height was set at $85 \mathrm{~cm}$, which then ranged from $\sim 86.7 \mathrm{~cm}$ for $20 \mathrm{~kg} / \mathrm{m}^{2}$ to $\sim 96 \mathrm{~cm}$ for $50 \mathrm{~kg} / \mathrm{m}^{2}$ when including the BMI thicknesses 


\begin{tabular}{|c|c|}
\hline $\begin{array}{c}\text { Sensor } \\
\text { No. }\end{array}$ & $\begin{array}{c}\text { Anatomical area / Body Segment } \\
\text { location } \\
\text { (sensor acronym) } \\
\text { Head (HEA) }\end{array}$ \\
\hline 2 & \begin{tabular}{c} 
Upper torso (UT) \\
\hline $3 \& 4$
\end{tabular} \\
\hline $5 \& 6$ & $\begin{array}{c}\text { Centre of humerus / Left \& Right } \\
\text { Upper arm (LUA or RUA) }\end{array}$ \\
\hline $7 \& 8$ & $\begin{array}{c}\text { Proximal end of ulna / Left \& Right } \\
\text { Forearm (LFA or RFA) }\end{array}$ \\
\hline $9 \& 10$ & $\begin{array}{c}\text { Dorsal side of hand / Left \& Right } \\
\text { Hand (LHA or RHA) }\end{array}$ \\
\hline 11 & Lower torso (LT) \\
\hline
\end{tabular}

Fig. 1 The IMU positions of the motion capture system highlighted with squares

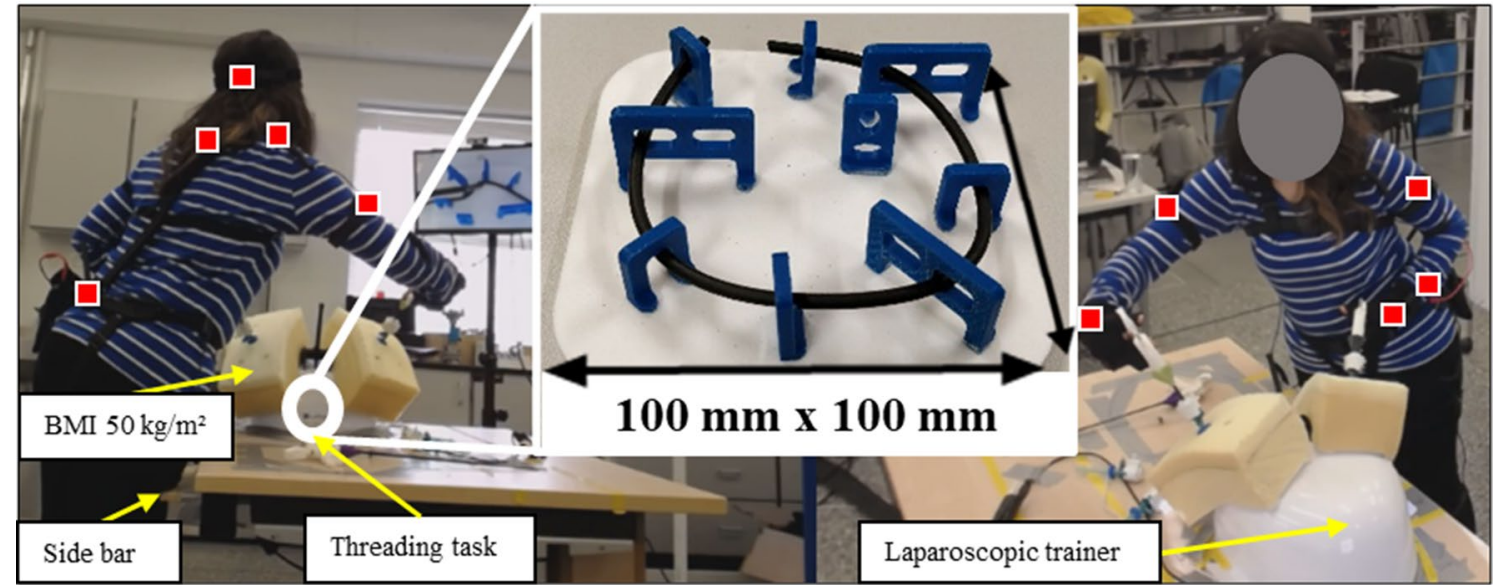

Fig. 2 Experimental setup with BMI $50 \mathrm{~kg} / \mathrm{m}^{2}$ analogue attached to laparoscopic trainer while completing a threading task. The visible IMUs in this figure have been highlighted with squares on the participant

to ensure optimized table ergonomics. The monitor height was also varied with participant height to ensure the monitor was approximately aligned with eye level [22].

\section{Testing procedure}

The testing procedure consisted of performing a standard threading task typically used for laparoscopic training [23], when exposed to the different BMI levels. To complete the task, every participant was required to insert the thread into each of the outer frames until all eight outer frames were threaded (Fig. 2). A fixed laparoscope provided real-time visual feedback of the threading task on the monitor (Fig. 2).

The testing procedure required each participant to complete each BMI level twice. A maximum time threshold was not implemented during the experiments because fatigue is known to have an effect on kinematics and the subsequent dynamic workload [24]. Each participant was allowed familiarization trials with no BMI model present and the implementation order of the BMI levels was randomized to reduce learning bias [25]. Between each trial, participants were allowed a minimum of three minutes of rest to avoid pre-task-related fatigue. 
Additional testing conditions were kept constant throughout the study including: the threading task distance from the ports within the trainer; port placement; laparoscope and its positioning and trocars. A contralateral port placement was selected as it has been shown to be a preferred setup among surgeons [26].

\section{Data analysis}

The accelerometer data was filtered using a $4^{\text {th }}$ order Butterworth bandpass filter with a range of $0.2-20 \mathrm{~Hz}$ to remove the effects of gravity and noise. In addition, the gyroscope data was filtered using a $4^{\text {th }}$ order Butterworth lowpass filter with a cut-off frequency of $20 \mathrm{~Hz}$ to remove the effects of noise [14]. All sensors were defined in the local coordinate system, therefore, isolating the motion of each segment where a sensor was positioned. Moreover, the kinematic data for each segment was expressed relative to its parent segment further up the kinematic chain, following the same conventions as described in [17].

\section{Kinematic variables}

To investigate the efficiency of motion, mean jerk, mean angular speed, and mean cumulative displacement (CD) were calculated for the upper body segments in Fig. 1. Mean CD also indicates the efficacy of motion when using $20 \mathrm{~kg} / \mathrm{m}^{2}$ as the benchmark. Further, the total time taken to complete the task and CD were used as overall measures of dynamic workload.

Linear jerk $|\mathrm{J}|$ was computed by finding the magnitude of the first order differential of each component in the acceleration vector $\left(a_{x}, a_{y}, a_{z}\right)$ [11]. Angular speed $|\omega|$ was calculated by finding the magnitude of the angular velocity vector $\left(\omega_{x}, \omega_{y}, \omega_{z}\right)$. Displacement of upper body segments was calculated by double integrating the acceleration vector for each segment [12]. The magnitude of the displacement vector $\left(s_{x}, s_{y}, s_{z}\right)$ for each segment was computed and summed to find $\mathrm{CD}$ [27].

\section{Subjective feedback}

To understand whether the experimental setup and BMI models were realistic, a post testing questionnaire was included. The questionnaire comprised of five questions (Table 1). All questions were asked to the intermediate and expert surgeons (grouped as 'experienced'); however, only questions 2 and 5 were asked to the novices because of their lack of previous experience. The questionnaire was answered once by each participant, after all trials had been completed.

Participant responses were recorded on a 7-point Likert scale. A response of 6 indicated an exact representation/ significant impact on movement/significant impact on difficulty, depending on the question, 3 represented 'neutral' and 0 indicated a completely unrepresentative setup/no impact on movement/no impact on difficulty, depending on the question.

\section{Statistical analysis}

Statistical analysis was completed in SPSS (IBM SPSS Statistics, v. 24, IBM Corp., Armonk, NY). The responses (Fig. 3) were calculated by grouping the participants into their respective experience groups and taking the mean of the trials per BMI. Due to the small intra-experience subsamples, normal distributions could not be assumed for parametric analysis; therefore, non-parametric analysis was performed by individually grouping all data by a single independent variable. When grouped by dependent samples (by BMI level), a Friedman's two-way ANOVA was performed. When grouped by independent samples (by experience level), a Kruskal-Wallis test was performed. Both tests were performed for each anatomical area and kinematic variable. Where significant main effects were found, pairwise comparisons were carried out with Bonferroni correction. An alpha level of $\alpha \leq 0.05$ was set.

Table 1 Post testing questions

\begin{tabular}{ll}
\hline Question number & Question \\
\hline 1 & How representative was the foam thickness of the intended BMI level? \\
2 & To what degree did the different foam condition impact the difficulty of the task? \\
3 & In terms of 'movement feel' when manipulating the instruments inside the laparoscopic trainer, \\
& please rate how representative the foam was of body fat? \\
4 & To what degree was the threading task representative of performing real surgery? \\
5 & To what degree did wearing the suit affect your movements during the trials?
\end{tabular}


(A) Head

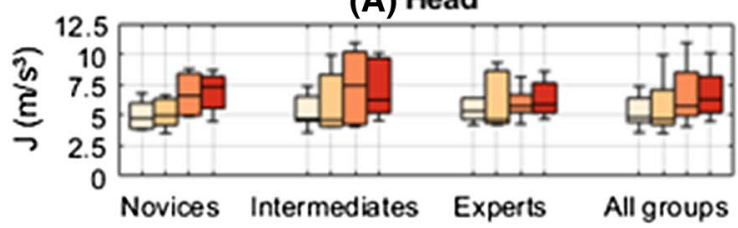

(B) Upper Torso

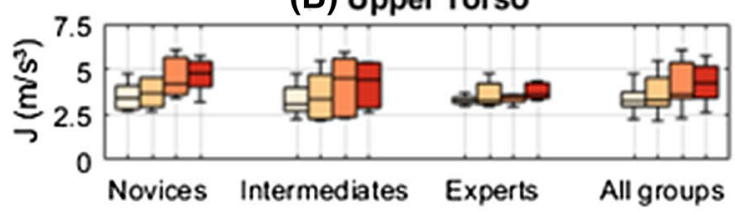

(C) Left Upperarm

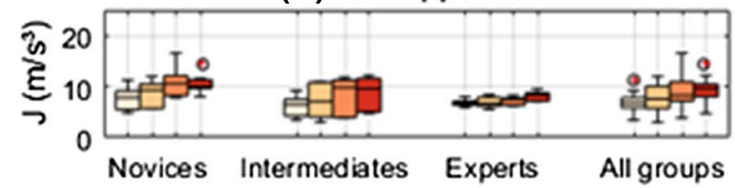

(D) Right Upperarm

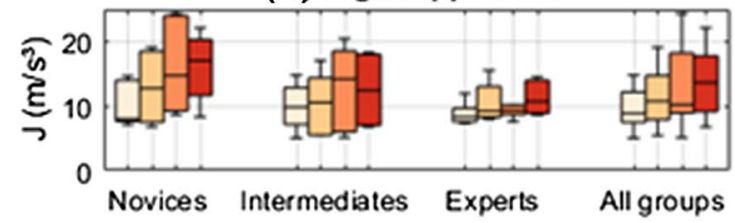

(E) Head

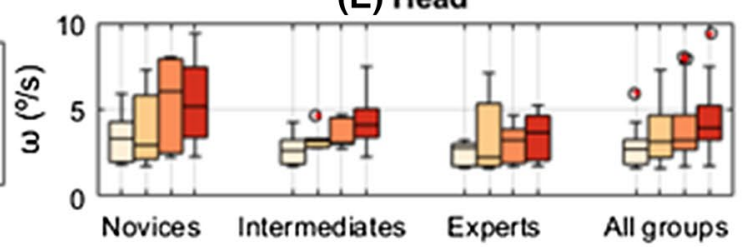

(F) Upper Torso

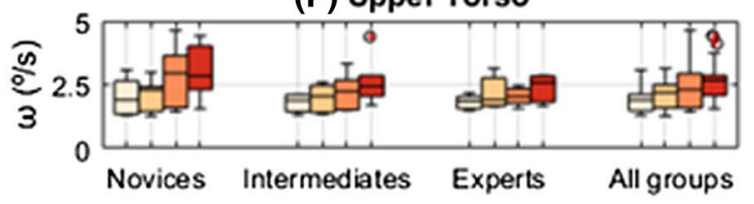

(G) Left Upperarm

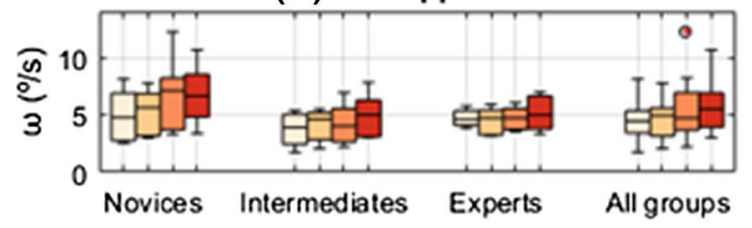

(H) Right Upperarm

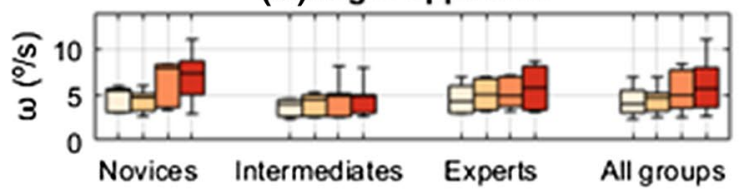

(I) Novices

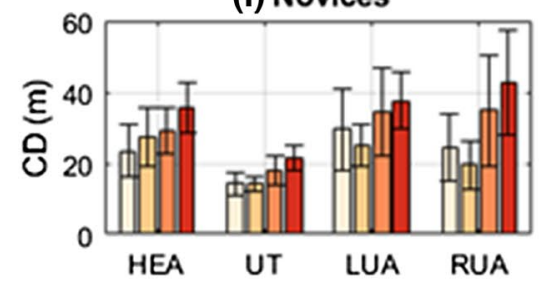

(J) Intermedtiates

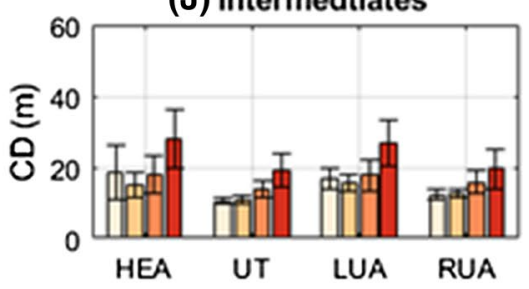

(K) Experts

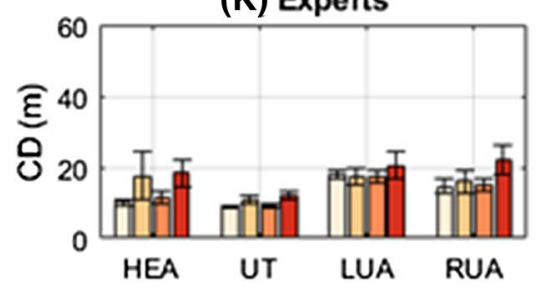

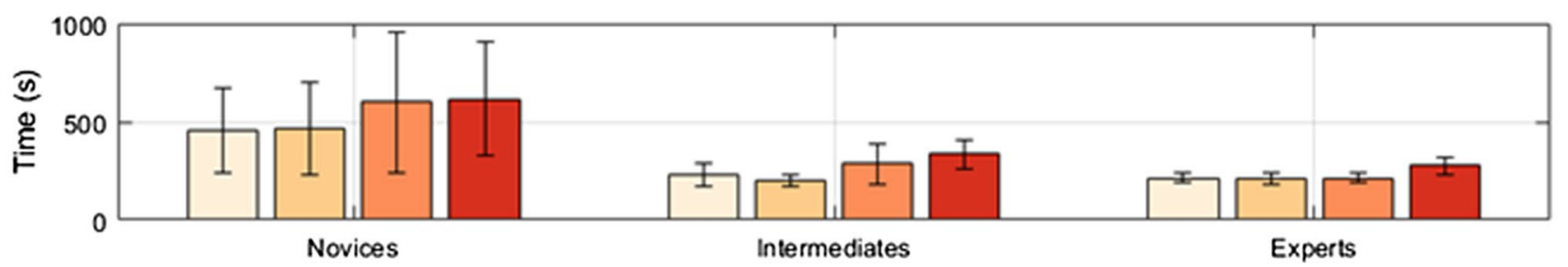

Fig. 3 Mean jerk (A-D) and mean angular speed (E-H) boxplots for the defined segments of all experience groups displayed separately and together. In addition, mean ( \pm standard error) cumulative displacement $(\mathrm{Cu}-\mathrm{Disp})$ of I) novices, J) intermediates and $\mathrm{K})$ experts, for the following body segments HEA = head, UT = torso, LUA = left

\section{Results}

Each BMI level was completed twice by nine of the participants, while a single novice completed each level once upper arm, RUA = right upper arm. Finally, L) mean ( \pm standard error) task completion times for novices, intermediates, and experts. (Note: the boxplots in Fig. 3 are of different Y-axis magnitudes to suitably display the data)

due to lengthy completion times which prevented the possibility of test repeats. Results for the head, torso, and two upper arms (sensors 1,2, 5 and 6) are presented due to the larger number of significant variances. 


\section{Kinematics and workload results}

Significant main effects of BMI level were seen for mean jerk, mean angular speed and cumulative displacement. Pairwise comparisons generally showed BMI $50 \mathrm{~kg} / \mathrm{m}^{2}$ significantly increased the magnitudes of all variables compared to the baseline in all body segments (Table 2). Significant main effects of experience level were also found in all kinematic variables, with the most significant of these differences being for cumulative displacement, where novices displayed larger values than experts for the head and torso. Cumulative displacement magnitudes between the BMI level extremes $\left(20 \mathrm{~kg} / \mathrm{m}^{2}<50 \mathrm{~kg} / \mathrm{m}^{2}\right)$ showed that $50 \mathrm{~kg} / \mathrm{m}^{2}$ significantly increased the distance travelled by all segments. There was also a significant main effect of BMI on task completion time $(p=0.004)$, with pairwise comparisons showing that tasks took significantly longer during BMI $50 \mathrm{~kg} / \mathrm{m}^{2}$ compared to $20 \mathrm{~kg} /$ $\mathrm{m}^{2}$ and $30 \mathrm{~kg} / \mathrm{m}^{2}$.

Generally, BMI $50 \mathrm{~kg} / \mathrm{m}^{2}$ caused upper body kinematics to significantly worsen compared to normal BMI models. Specifically, novices appeared to be markedly affected by BMI level once the BMI model reached $40 \mathrm{~kg} / \mathrm{m}^{2}$ and intermediates were also noticeably affected in some cases, but not as extensively until BMI $50 \mathrm{~kg} / \mathrm{m}^{2}$, whereas expert participants appeared affected only for BMI $50 \mathrm{~kg} / \mathrm{m}^{2}$ with the lower BMI levels producing relatively consistent results. These results confirmed the hypotheses that significant deterioration in kinematics can be observed when surgeons are subjected to larger BMI models and that less experienced surgeons display worse kinematics.

\section{Questionnaire responses}

Post testing questionnaire responses indicated a positive response to the experimental methodology, supporting the ecological validity of the BMI models used, although less so the threading task protocol (Fig. 4).

\section{Discussion}

The key purpose of this study was to objectively measure the effect of simulated obesity and severe obesity on the kinematics and dynamic workload of surgeons of varying experience levels. This research builds on previous work conducted into understanding the physical impact of MIS on the surgeon $[9,10,17]$. Mean jerk, angular speed and cumulative displacement magnitudes significantly increased in line with increasing model BMI for the head, torso, and both upper arms across all experience groups (Fig. 4, Table 2). Further, surgeon experience had a significant main effect on upper body kinematics, reinforcing previous findings that novices exhibited worse kinematics compared to more experienced surgeons [23].

The BMI $50 \mathrm{~kg} / \mathrm{m}^{2}$ model caused significantly greater mean jerk magnitudes in all segments, indicating that all participants struggled to smoothly accelerate between changes in body position as compared to the baseline and obese model (Fig. 3A-D). Acceleration without jerk is a consequence of a static load or force such as gravity; therefore, jerk is felt as the increasing or decreasing change in force on the body [28]. A significant increase in jerk in conjunction

Table 2 Statistical analysis

\begin{tabular}{|c|c|c|c|}
\hline $\begin{array}{l}\text { Body segments and } \\
\text { kinematic parameters }\end{array}$ & $\begin{array}{l}\text { Kruskal Wallis test (denoted by } \mathbf{K} \text { ) and } \\
\text { pairwise experience group comparisons } \\
\text { (denoted by e.g. Exp/Int/Nov) }\end{array}$ & $\begin{array}{l}\text { Friedman's test (denoted by } \mathbf{F} \text { ) and } \\
\text { pairwise BMI comparisons (denoted by } \\
\text { e.g. 20/50) }\end{array}$ & \\
\hline \multirow[t]{3}{*}{ Head } & Jerk $(\mathrm{J})$ & $\mathbf{K}: p=0.998$ & $\begin{array}{c}\text { F: } p=0.001, \mathbf{2 0} / \mathbf{4 0}: p=0.032 \\
\text { 20/50: } p=0.017, \mathbf{3 0} / \mathbf{4 0}: \\
p=0.039, \mathbf{3 0} / \mathbf{5 0}: p=0.021\end{array}$ \\
\hline & Ang speed $(\omega)$ & $\mathbf{K}: p=0.088$ & $\mathbf{F}: p=0.012, \mathbf{2 0} / \mathbf{5 0}: p=0.017$ \\
\hline & $\mathrm{Cu}-\mathrm{Disp}(\mathrm{CD})$ & $\mathbf{K}: p=0.001, \mathbf{N o v} / \mathbf{E x p}: p=0.001$ & $\mathbf{F}: p=0.008, \mathbf{2 0} / \mathbf{5 0}: p=0.007$ \\
\hline \multirow[t]{3}{*}{ Torso } & Jerk $(\mathrm{J})$ & $\mathbf{K}: p=0.176$ & $\begin{array}{l}\text { F: } p=0.003, \mathbf{2 0} / \mathbf{4 0}: p=0.047 \\
\text { 20/50: } p=0.026\end{array}$ \\
\hline & Ang speed $(\omega)$ & $\mathbf{K}: p=0.279$ & $\mathbf{F}: p=0.005, \mathbf{2 0} / \mathbf{5 0}: p=0.003$ \\
\hline & $\mathrm{Cu}-\mathrm{Disp}(\mathrm{CD})$ & $\mathbf{K}: p=0.006$, Nov/Exp: $p=0.004$ & $\mathbf{F}: \quad p=0.005, \mathbf{2 0} / \mathbf{5 0}: p=0.004$ \\
\hline \multirow[t]{3}{*}{ Left upper arm } & Jerk $(J)$ & $\mathbf{K}: p=0.010, \mathbf{N o v} / \mathbf{E x p}: p=0.011$ & $\begin{array}{l}\text { F: } p=0.003, \mathbf{2 0} / \mathbf{4 0}: p=0.021 \\
\text { 20/50: } p=0.011\end{array}$ \\
\hline & Ang speed $(\omega)$ & K: $p=0.028$, Nov/Int: $p=0.024$ & $\mathbf{F}: p=0.077$ \\
\hline & $\mathrm{Cu}-\mathrm{Disp}(\mathrm{CD})$ & $\mathbf{K}: p=0.086$ & $\mathbf{F}: p=0.148$ \\
\hline \multirow[t]{3}{*}{ Right upper arm } & Jerk $(\mathrm{J})$ & $\mathbf{K}: p=0.075$ & $\mathbf{F}: p=0.011, \mathbf{2 0} / \mathbf{5 0}: p=0.039$ \\
\hline & Ang speed $(\omega)$ & K: $p=0.034$, Nov/Int: $p=0.034$ & $\mathbf{F}: \mathrm{p}=0.006,20 / 40: p=0.021$ \\
\hline & $\mathrm{Cu}-\mathrm{Disp}(\mathrm{CD})$ & $\mathbf{K}: p=0.081$ & $\mathbf{F}: p=0.044, \mathbf{3 0} / \mathbf{5 0}: p=0.05$ \\
\hline
\end{tabular}




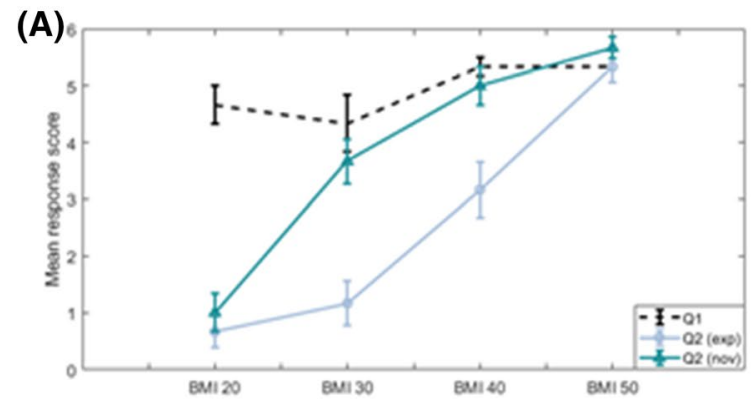

Fig. 4 A. Mean ( \pm Standard error) questionnaire responses for questions 1 and 2 (Table 1), B. Mean ( \pm Standard error) questionnaire responses for questions 3,4 and 5 (Table 1). All questions were asked

with longer task completion times indicates the frequency and forcefulness of movements performed by the upper body increased, indicating less efficient performances that induced higher levels of required work to compensate for the larger model thickness and increased resistance against laparoscopic tool movement. Moreover, since degradation in motion control and smoothness were observed, and fatigue is a direct contributor to these [28], significant increases in jerk magnitudes indicate a more physically demanding task.

A similar set of statistical results were found for the angular speed of the head, torso, and dominant upper arm, where severely obese models caused significantly faster angular motion. Faster angular motion in conjunction with jerkier and more forceful movements suggests that these participant groups needed to repeatedly correct their upper arm movements to achieve the desired instrument manipulation [29]. The unexpected variability and skewed distribution in jerk and angular speed magnitudes within the expert group during $30 \mathrm{~kg} / \mathrm{m}^{2}$ (Fig. 2), indicates that a single expert participant found this BMI level challenging kinematically, producing results analogous with the novices. This result is the product of a small sample size, and if a larger sample had been recruited these results would likely be outliers. In addition, these results also emphasize that even expert surgeons produce kinematics that could be optimised.

The BMI $50 \mathrm{~kg} / \mathrm{m}^{2}$ model also had a significant negative effect on motion efficacy leading to larger cumulative displacement magnitudes (Fig. 3I-K). The effect of larger model circumferences at higher BMI levels caused accentuated motion altering optimal motion patterns represented by the baseline, as well as contributing to the variations in the other parameters. The significant increases in torso and upper arm cumulative displacement during BMI $50 \mathrm{~kg} /$ $\mathrm{m}^{2}$ compared to $20 \mathrm{~kg} / \mathrm{m}^{2}$ indicate that these commonly reported at-risk areas struggled to adapt to the larger models compared to other areas of the upper body [7]. A larger magnitude for cumulative displacement is an increase in the total distance travelled; thus, a significantly larger dynamic

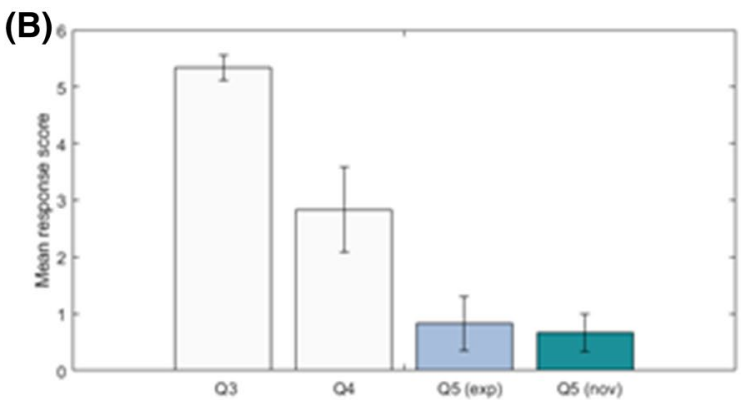

once per participant, at the end of all trials. Q2 and Q5 were asked to both experienced and novice participants

workload was incurred at BMI $50 \mathrm{~kg} / \mathrm{m}^{2}$ compared to the baseline and obese model.

The highly correlated results in all kinematic and workload-related variables indicate that BMI level had a considerable impact on a surgeon's ability to perform to the optimal standard represented by the baseline. The thicker foam medium for the higher BMI models may have diminished the shoulder proprioceptive relationship with the trainer and led to the observed torso and upper arm behaviour [30]. All participants had previous experience of a laparoscopic training environment; however, this had not included BMI models (i.e. $\geq 30 \mathrm{~kg} / \mathrm{m}^{2}$ ). Thus, any previous reinforced conscious or unconscious proprioceptive influence on the neuromuscular system during laparoscopic training may have naturally de-stabilized upper arm motion due to the unconventional high BMI training environment. Moreover, the effect of a thicker foam medium is likely to have restricted trocarinstrument movement supported by the perceived increase in task difficulty with increasing BMI (Fig. 4). This effect worked against instrument manipulation, induced more jerk (Fig. 3A-D), higher angular speeds (Fig. 3E-H), larger cumulative displacements (Fig. 3I-K), and longer task durations (Fig. 3L) as well as impairing the kinesthetic relationship between surgeon and laparoscopic trainer. Also, it could be argued that this is likely to be a replicated effect that is also seen in a clinical setting, caused by dense abdominal subcutaneous adiposity.

The key contribution and findings of this study are that performing procedures on patients with high BMIs (BMI $>40 \mathrm{~kg} / \mathrm{m}^{2}$ ) creates a significantly more demanding task that induces higher levels of fatigue compared to normal BMIs $\left(20 \mathrm{~kg} / \mathrm{m}^{2}\right)$ even for exercises of short duration. An increase in the levels of fatigue during physical tasks has been shown to increase the incidence of MSDs [7]. The results pertaining to the intermediate and expert groups offer the most clinical relevance within this study, as these groups have been regularly exposed to patients with a high BMI in surgery and are likely to have developed kinematic 
responses to manage such scenarios. However, these findings are concerning as MIS surgeons are exposed to patients with high BMIs with increasing regularity [10] and since many surgical procedures will have durations in excess of an hour, the cumulative impact of dynamic workload and fatigue with time may result in reduced surgical performance and worse patient outcomes. Investigation of surgeon ergonomics in the live surgery setting is needed to explore this impact further and develop interventions that can mitigate these effects. Trainee surgeons do need to gain experience in performing procedures on patients with a range of BMIs, but our study highlights that this group need training in ergonomic positioning rather than solely on improving their technical performance since suboptimal techniques could become ingrained and increase the risk of MSDs in their future careers.

The subjective feedback gathered from the participants regarding the experimental setup and BMI models provided a largely positive response to the conducted methodology. The methodological strengths include the realism of the BMI models in terms of movement feel and thickness, as well as the objective instrumentation system having a negligible effect on surgeon kinematics. The threading task was reported to be the most challenging; such tasks are primed for specific surgical skill development rather than surgery itself; however, other standardized tasks or simulated procedures should be considered in the future testing.

There are limitations that should be acknowledged when interpreting the results from this study. The relatively small heterogenous cohort of surgeons and completion of one simulated experimental task could reduce the generalizability of the relationships between BMI, experience level and upper body kinematics. The use of foam as the material to simulate adipose tissue does not fully replicate the material properties of adipose tissue. Further, the models also did not account for the differences in adipose tissue distribution (visceral/ subcutaneous), nor how increased intra-abdominal adiposity effected surgeon kinematics.

However, the subjective feedback gathered largely supports foam as an appropriate representation. The subjective feedback on each BMI level was gathered post experiments rather than after each BMI level. Additionally, the contralateral port placement may not be routinely used by some surgeons who prefer to vary port sites depending on patient BMI. Nevertheless, the setup was implemented through the recommendation from practicing gynaecologists [26]. This study considered only upper body kinematics, the effect of patients with obesity on the wider biomechanical impact of surgeons is also of relevance to surgeon wellbeing. Finally, despite the mixed gender of the participant cohort, the impact of patient BMI on male/female surgeons was not investigated, which is an aspect of bariatric LS that should be considered in the future studies.

\section{Conclusion}

Performing LS on high (40 and $50 \mathrm{~kg} / \mathrm{m}^{2}$ ) BMI models is physically more demanding compared to performing on 20 and $30 \mathrm{~kg} / \mathrm{m}^{2}$ models. More specifically, high BMI models degraded the efficiency and efficacy of surgeon head, torso and upper arm movement and increased their dynamic workload. Novice surgeons need exposure to high BMI models early in their career, to minimize the increase in workload through the optimization of kinematic performance while still in training. Furthermore, with increasing worldwide obesity levels, additional ergonomic training and support should be considered for surgeons who perform LS since this may reduce their risk of future MSDs.

Acknowledgment The authors would like to thank the surgeons for their participation.

Author contributions All authors associated with this manuscript were involved with the study design, implementation, or preparation of the manuscript. Specifically, R. Sers, S. Forrester, M. Zecca and E. Moss contributed towards the planning and design of the study. R. Sers and S. Ward setup the study and acquired the data. R. Sers performed the data analysis and all authors contributed towards preparation of the manuscript.

Funding This work has been partially supported by the LU-HEFCE Catalyst Grant, the LU-EESE startup grant, and by the Research Studentship awarded to R. Sers by the Doctoral College of Loughborough University, UK.

Code availability The code written to perform this analysis can be found: https://doi.org/10.24433/CO.7129140.v1

\section{Declarations}

Conflict of interest Ryan Sers, Steph Forrester, Stephen Ward and Massimiliano Zecca have no conflicts of interest or financial ties to disclose. Esther Moss performs da'Vinci robotic gynecological surgery (Intuitive Surgical) and is a member of the British and Irish Association of Robotic Surgeons (BIARGS), which is supported by robotic/laparoscopic companies to hold education/training events. Esther Moss has served on advisory boards for Inivata and GlaxoSmithKline; received speaker fees from GlaxoSmithKline; has received research grants from Hope Against Cancer and Intuitive Surgical for unrelated work.

Ethical approval \& consent to participate This study was conducted at Loughborough University, UK. Ethical approval was granted by the Loughborough University Ethics Approvals Sub-Committee and all participants provided voluntary informed consent prior to testing.

Open Access This article is licensed under a Creative Commons Attribution 4.0 International License, which permits use, sharing, adaptation, distribution and reproduction in any medium or format, as long as you give appropriate credit to the original author(s) and the source, provide a link to the Creative Commons licence, and indicate if changes were made. The images or other third party material in this article are included in the article's Creative Commons licence, unless indicated otherwise in a credit line to the material. If material is not included in 
the article's Creative Commons licence and your intended use is not permitted by statutory regulation or exceeds the permitted use, you will need to obtain permission directly from the copyright holder. To view a copy of this licence, visit http://creativecommons.org/licenses/by/4.0/.

\section{References}

1. NICE: National Institute for Health and Care Excellence, Obesity : identification, assessment and management, 2020

2. NHS Digital, Statistics on Obesity, Physical Activity and DietEngland, Stat. Obesity, Phys. Act. Diet-Engl. (2018). https://digit al.nhs.uk/data-and-information/publications/statistical/statisticson-obesity-physical-activity-and-diet/statistics-on-obesity-physi cal-activity-and-diet-england-2018 (accessed August 15, 2019)

3. EASO, The European Association for the Study of Obesity, (2018). https://easo.org/research/

4. Bianchini F, Kaaks R, Vainio H (2002) Overweight, obesity, and cancer risk. Lancet Oncol 3:565-574. https://doi.org/10.1016/ S1470-2045(02)00849-5

5. Moss EL, Morgan G, Martin AP, Sarhanis P, Ind T (2020) Surgical trends, outcomes and disparities in minimal invasive surgery for patients with endometrial cancer in England: A retrospective cohort study. BMJ Open 10:1-9. https://doi.org/10.1136/bmjop en-2019-036222

6. Nguyen NT, Ho HS, Smith WD, Philipps C, Lewis C, De Vera RM, Berguer R (2001) An ergonomic evaluation of surgeons' axial skeletal and upper extremity movements during laparoscopic and open surgery. Am J Surg 182:720-724

7. Alleblas CCJ, de Man AM, van den Haak L, Vierhout ME, Jansen FW, Nieboer TE (2017) Prevalence of musculoskeletal disorders among surgeons performing minimally invasive surgery. Ann Surg 266:905-920. https://doi.org/10.1097/SLA.0000000000002223

8. Franasiak J, Ko EM, Kidd J, Secord AA, Bell M, Boggess JF, Gehrig PA (2012) Physical strain and urgent need for ergonomic training among gynecologic oncologists who perform minimally invasive surgery. Gynecol Oncol 126:437-442. https://doi.org/10. 1016/j.ygyno.2012.05.016

9. Liang Z, Gerull WD, Wang R, Zihni A, Ray S, Awad M (2019) Effect of patient body mass index on laparoscopic surgical ergonomics. Obes Surg 29:1709-1713. https://doi.org/10.1007/ s11695-019-03748-0

10. Moss EL, Sarhanis P, Ind T, Smith M, Davies Q, Zecca M (2019) Impact of obesity on surgeon ergonomics in robotic and straightstick laparoscopic surgery. J Minim Invasive Gynecol. https://doi. org/10.1016/j.jmig.2019.07.009

11. Saito K, Zecca M, Sessa S, Lin Z, Bartolomeo L, Cosentino S, Petersen K, Ishii H, Ikai T, Takanishi A (2012) Assessment of walking quality by using Inertial Measurement Units. In: Int. Conf. Innov. Eng. Syst., pp. 13-18.

12. Roetenberg D, Slycke PJ, Veltink PH (2007) Ambulatory position and orientation tracking fusing magnetic and inertial sensing. IEEE Trans Biomed Eng 54:883-890. https://doi.org/10.1109/ TBME.2006.889184

13. Yu D, Abdelrahman AM, Buckarma EH, Lowndes BR, Gas BL, Finnesgard EJ, Abdelsattar JM, Pandian TK, El Khatib M, Farley DR, Hallbeck S Mental and physical workloads in a competitive laparoscopic skills training environment : A Pilot Study, in: Hum. Factors J. Hum. Factors Ergon. Soc., 2015: pp. 508-512 https:// doi.org/10.1177/1541931215591109

14. Sers R, Forrester S, Moss E, Ward S, Ma J, Zecca M (2020) Validity of the Perception Neuron inertial motion capture system for upper body motion analysis. Meas J Int Meas Confed. https://doi. org/10.1016/j.measurement.2019.107024

15. NOITOM, Axis Neuron Userguide, (2015). https://shopcdn.noitom.com.cn/software/AxisUserGuideFinal0923.pdf (accessed March 20, 2018)

16. Sers R (2021) Motion analysis using the Perception Neuron motion capture system. https://doi.org/10.24433/CO.7129140.v1

17. Sers R, Forrester S, Zecca M, Ward S, Moss E (2021) The ergonomic impact of patient body mass index on surgeon posture during simulated laparoscopy. Appl Ergon. https://doi.org/10.1016/j. apergo.2021.103501

18. Roopakala MS, Suresh A, Ashtalakshmi S, Ashok G, Anand WDS (2009) Anthropometric measurements as predictors of intraabdominal fat thickness, Indian. J Physiol Pharmacol 53:259-264. https://doi.org/10.1051/0004-6361:20021171

19. Mohammed S, Polymeros K, Wickham-Joseph R, Luqman I, Charadva C. Morris T, Collins A, Moss E (2021) Comparing characteristics of endometrial cancer in South Asian and White ethnicity women in England (under review), Cancers (Basel)

20. Burnett J, Clift L, Clift M (2009) NHS Purchasing and Supply Agency-Buyers ' Guide: Operating tables

21. Van Veelen MA, Kazemier G, Koopman J, Goossens RHM, Meijer DW (2002) Assessment of the ergonomically optimal operating surface height for laparoscopic surgery. J Laparoendosc Adv Surg Tech 12:47-52. https://doi.org/10.1089/109264202753486 920

22. Matern U, Kehl K, Giebmeyer C, Faist M (2002) Monitor position in Laparoscopic Surgery, In: Hum. Factors J Hum Factors Ergon Soc pp 1506-1510

23. Lin Z, Uemura M, Zecca M, Sessa S, Ishii H, Tomikawa M, Hashizume M, Takanishi A (2013) Objective skill evaluation for laparoscopic training based on motion analysis. IEEE Trans Biomed Eng 60:977-985. https://doi.org/10.1109/TBME.2012. 2230260

24. Sparto P, Parnianpour M, Reinsel T, Sheldon S (1976) The effect of fatigue on multijoint kinematics and load sharing during a repetitive lifting test, Spine (Phila. Pa 22(1997):2647-2654

25. Thomas KE, König CJ (2018) Knowledge of previous tasks: Task similarity influences bias in task duration predictions. Front Psychol 9:1-14. https://doi.org/10.3389/fpsyg.2018.00760

26. Hignett S, Gyi D, Calkins L, Jones L, Moss EL (2017) Human factors evaluation of surgeons' working positions for gynecologic minimal access surgery. J Minim Invasive Gynecol 24:1177-1183. https://doi.org/10.1016/j.jmig.2017.07.011

27. Han S (2010) Measuring displacement signal with an accelerometer. J Mech Sci Technol 24:1329-1335. https://doi.org/10.1007/ s12206-010-0336-1

28. Zhang L, Diraneyya MM, Ryu JH, Haas CT, Abdel-Rahman EM (2019) Jerk as an indicator of physical exertion and fatigue. Autom Constr 104:120-128. https://doi.org/10.1016/j.autcon. 2019.04.016

29. Vu VH, Isableu B, Berret B (2016) Adaptive use of interaction torque during arm reaching movement from the optimal control viewpoint. Sci Rep 6:1-20. https://doi.org/10.1038/srep38845

30. Wilk KE, Macrina LC, Arrigo C (2012) Physical Rehabilitation of the Injured Athlete-12 Shoulder Rehabilitation, Fourth Edi, Elsevier Inc., 2012https://doi.org/10.1016/B978-1-4377-2411-0. 00012-5

Publisher's Note Springer Nature remains neutral with regard to jurisdictional claims in published maps and institutional affiliations. 